\title{
Expression of the skeletal muscle dystrophin-dystroglycan complex and syntrophin-nitric oxide synthase complex is severely affected in the type 2 diabetic Goto-Kakizaki rat
}

\author{
Claire Mulvey $^{\mathrm{a}, \mathrm{b}}$, Erika Harno ${ }^{\mathrm{a}}$, Alan Keenan ${ }^{\mathrm{a}}$, Kay Ohlendieck ${ }^{\mathrm{b}, *}$ \\ ${ }^{a}$ Department of Pharmacology, Conway Institute of Biomolecular and Biomedical Science, University College Dublin, Belfield, \\ Dublin 4, Ireland \\ ${ }^{\mathrm{b}}$ Department of Biology, National University of Ireland, Maynooth, County Kildare, Ireland
}

Received 19 May 2005; received in revised form 27 June 2005; accepted 30 June 2005

\begin{abstract}
The inability of insulin to stimulate glucose metabolism in skeletal muscle fibres is a classic characteristic of type 2 diabetes. Using the non-obese Goto-Kakizaki rat as an established animal model of this type of diabetes, sucrose gradient centrifugation studies were performed and confirmed the abnormal subcellular location of the glucose transporter GLUT4. In addition, this analysis revealed an unexpected drastic reduction in the surface membrane marker $\beta$-dystroglycan, a dystrophin-associated glycoprotein. Based on this finding, a comprehensive immunoblotting survey was conducted which showed a dramatic decrease in the Dp427 isoform of dystrophin and the $\alpha / \beta$-dystroglycan subcomplex, but not in laminin, sarcoglycans, dystrobrevin, and excitation-contraction-relaxation cycle elements. Thus, the backbone of the trans-sarcolemmal linkage between the extracellular matrix and the actin membrane cytoskeleton might be structurally impaired in diabetic fibres. Immunohistochemical studies revealed that the reduction in the dystrophin-dystroglycan complex does not induce obvious signs of muscle pathology, and is neither universal in all fibres, nor fibre-type specific. Most importantly, the expression of $\alpha$-syntrophin and the syntrophinassociated neuronal isoform of nitric oxide synthase, nNOS, was demonstrated to be severely reduced in diabetic fibres. The loss of the dystrophin-dystroglycan complex and the syntrophin-nNOS complex in selected fibres suggests a weakening of the sarcolemma, abnormal signalling and probably a decreased cytoprotective mechanism in diabetes. Impaired anchoring of the cortical actin cytoskeleton via dystrophin might interfere with the proper recruitment of the glucose transporter to the surface membrane, following stimulation by insulin or muscle contraction. This may, at least partially, be responsible for the insulin resistance in diabetic skeletal muscles.
\end{abstract}

(C) 2005 Elsevier GmbH. All rights reserved.

Keywords: Dystrophin; Dystrophin-glycoprotein complex; Dystroglycan; Syntrophin; Type 2 diabetes; Insulin resistance; Goto-Kakizaki rat; nNOS; GLUT4; Sarcolemma

\footnotetext{
*Corresponding author. Tel.: + 35317083842 ; fax: +35317083845 .

E-mail address: kay.ohlendieck@nuim.ie (K. Ohlendieck).
}

\section{Introduction}

The inability of peripheral target tissues to properly respond to insulin is a principal feature of type 2 diabetes (Petersen and Shulman, 2002). Pathophysiological 
defects in tissue sensitivity to insulin affect the liver, adipose tissue and muscle fibres (Moller, 2001). Since skeletal muscles are responsible for up to $80 \%$ of whole body insulin-stimulated glucose disposal, abnormal hormone signalling in muscle fibres plays a central role in insulin resistance (Boord et al., 2001). This signalling defect affects millions of diabetic patients worldwide (Zimmet et al., 2001) and has been estimated to rise even further in developed countries (King et al., 1998). Insulin-resistant type 2 diabetes represents an extremely complex clinical disorder (Scheen, 2003) that is influenced by both genetic factors (Almind et al., 2001) and modern lifestyle (Sowers and Frohlich, 2004). Recent studies with tissue-specific ablation of the insulin receptor have revealed that both canonical insulin targets, e.g. skeletal muscle and adipose tissue, and non-canonical insulin targets, e.g. liver, pancreas and brain tissues, may contribute in distinctly different ways to clinical insulin resistance (Okamoto and Accili, 2003). The insulin receptor represents a tyrosine kinase, whereby insulin binding to the $\alpha$-subunits causes the $\beta$-subunits to autophosphorylate, thus activating the catalytic activity of the receptor complex. The activated insulin receptor phosphorylates a number of different intracellular targets, e.g. insulin receptor substrate 1 (IRS1). IRS1 serves as a docking molecule for the recruitment and activation of other signalling elements with Src homology 2 domains, such as the growth factor receptorbound element Grb2, that ultimately mediates control of intermediary metabolism by insulin (Schmitz-Peiffer and Whitehead, 2003). Subsequent steps in the insulin receptor pathway include IRS1-associated phosphoinositide-3-kinase activity, Akt kinase serine phosphorylation and glucose transporter activation. Thus, recruitment of signalling molecules by the activated insulin receptor is an extremely complex scenario and the many steps and interactions with other surface protein species have not yet been fully elucidated.

The rate-limiting step in skeletal muscle glucose metabolism is represented by glucose transportation. Within the glucose transporter family of proteins, the insulin-sensitive type 4 glucose transporter, usually referred to as GLUT4, is the principal isoform in muscle (Cushman et al., 1998). Previous studies have demonstrated co-localization of GLUT4 vesicles with a dystrophin-rich membrane following insulin stimulation of skeletal muscle fibres (Kahn et al., 1991). It was therefore of interest to evaluate the status of members of the dystrophin-glycoprotein complex in diabetic muscle fibres. In addition, Grb2, an adapter protein involved in signal transduction, was shown to directly interact with the dystrophin-associated dystroglycans and syntrophins (Yang et al., 1995; Oak et al., 2001). Glucose transport is also stimulated by skeletal muscle contraction involving nitric oxide and cGMP as signalling intermediates (Etgen et al., 1997). This makes investigations into the role of the different subtypes of nitric oxide synthase in skeletal muscle a key issue for understanding the various pathways that regulate GLUT4 translocation to the surface membrane. The nitric oxide synthase isoform nNOS has been shown to interact with dystrophin-associated proteins (Grozdanovic and Baumgarten, 1999), warranting an investigation of syntrophin-linked nNOS in diabetic muscle fibres. Since primary or secondary abnormalities in the dystrophin-glycoprotein complex are the underlying cause of various neuromuscular diseases, including Duchenne muscular dystrophy, Becker's muscular dystrophy, congenital muscular dystrophy, and certain forms of limbgirdle muscular dystrophy (Campbell, 1995; Ohlendieck, 1996), impaired muscle glucose metabolism and/or skeletal muscle weakness observed in diabetic patients (Andersen et al., 2004) could possibly be related to abnormal expression levels of the dystrophin complex and its many associated elements.

The non-obese Goto-Kakizaki (GK) rat model of type 2 diabetes was employed in this study. The spontaneously diabetic GK rat represents a well-established animal disease model (Kitahara et al., 1978), which demonstrates increased blood glucose levels without alterations in body weight or non-fasting plasma insulin level (Witte et al., 2002). It could be argued therefore, that GK tissues are a suitable source for the investigation of fundamental mechanisms of diabetes, in the absence of complicating factors such as obesity. Severe pathophysiological symptoms including defects in insulin secretion and peripheral insulin resistance usually occur by 4 weeks of age (Abdel-Halim et al., 1994; Portha et al., 1991). GK skeletal muscles appear to exhibit a reduced percentage of oxidative fibres (Yasuda et al., 2002) and also show fibre type-specific defects, with IRS1 and PI3K activity decreased primarily in oxidative muscles (Song et al., 1999). Activities of insulin signalling intermediates including PI3K, PKB/Akt and ERK were found to be impaired in GK muscle (Steiler et al., 2003; Krook et al., 1997). In addition, insulin receptor autophosphorylation and IRS1 tyrosine phosphorylation are inhibited in the GK rat (Dadke et al., 2000), suggesting chronically impaired signalling via the insulin pathway in skeletal muscle of this animal model. Here, we can show that the expression of the membrane cytoskeletal protein dystrophin and some of its associated elements are affected in diabetic GK skeletal muscle fibres. In analogy to muscular dystrophies, this molecular defect may at least partially explain impaired membrane signalling associated with the diabetic phenotype.

\section{Materials and methods}

\section{Materials}

Protogel acrylamide stock solutions were obtained from National Diagnostics (Atlanta, GA, USA). Bradford 
reagent and Silver Stain Plus kit were purchased from Bio-Rad Laboratories (Hemel Hempstead, Herts, UK). Immobilized $\mathrm{pH}$ gradient (IPG) strips of $\mathrm{pH} 3-10$ and IPG buffer of $\mathrm{pH} 3-10$ were obtained from Amersham Biosciences (Little Chalfont, Bucks, UK). Protran nitrocellulose membranes were from Schleicher and Schuell (Dassel, Germany) and protease inhibitors from Roche Diagnostics GmbH (Mannheim, Germany). Primary antibodies were purchased from Affinity Bioreagents, Golden, $\mathrm{CO}$ (mAb VIIID1 ${ }_{2}$ to fast calsequestrin, $\mathrm{mAb}$ IIH11 to the fast SERCA1 isoform of the sarcoplasmic reticulum $\mathrm{Ca}^{2+}$ ATPase, mAb IIID5 to the $\alpha_{1 S}$-subunit of the dihydropyridine receptor, $\mathrm{mAb} 34 \mathrm{C}$ to the ryanodine receptor and $\mathrm{mAb} 88 \mathrm{~B}$ to the $\delta$-subunit of the nicotinic acetylcholine receptor); Upstate Biotechnology, Lake Placid, NY (mAb C464.6 to the $\alpha_{1}$-subunit of the $\mathrm{Na}^{+} / \mathrm{K}^{+}$-ATPase, mAb VIA4 $4_{1}$ to $\alpha$-dystroglycan, $\mathrm{mAb} 3 \mathrm{~F} 2$ to the growth factor receptor-bound element Grb2, and pAb 06-528 to the neuronal isoform nNOS of nitric oxide synthase); Chemicon International, Temecula, CA (mAb MAB374 to glyceraldehyde-3-phosphate dehydrogenase, $\mathrm{mAb}$ $\mathrm{CT}-3$ to the $\beta$-subunit of the insulin receptor and $\mathrm{mAb}$ 8-63 to the IRS1); Novacastra Laboratories, Newcastle upon Tyne, UK (mAb NCL43 to $\beta$-dystroglycan, mAb NCL-DYS to dystrophin, and mAb NCL-aSARC to $\alpha$-sarcoglycan); Santa Cruz Biotechnology, Santa Cruz, $\mathrm{CA}$ (pAb c-15 to $\delta$-sarcoglycan and pAb v-19 to $\alpha$-dystrobrevin); Abcam Ltd., Cambridgeshire, UK (pAb Ab654 to the glucose transporter GLUT4); and Sigma Chemical Company, Poole, Dorset, UK (pAb AG-17 to $\alpha$-syntrophin and pAb L9393 to laminin). Affinity-purified and peroxidase-conjugated secondary antibodies were obtained from Chemicon International. Chemiluminescence (ECL) substrates and fluorescein- or rhodamine-conjugated anti-mouse and anti-rabbit $\mathrm{IgG}$ secondary antibodies were obtained from Pierce Biotechnologies (Rockford, IL). All other chemicals used, including those for MALDI-ToF mass spectrometry, were of analytical grade and purchased from Sigma Chemical Company.

\section{Animal model}

Freshly dissected hind limb skeletal muscle specimens from 12-week-old normal control Wistar rats and agematched GK diabetic rats (Kitahara et al., 1978) were received from the Biomedical Facility of the National University of Ireland, Dublin. Rats had been originally purchased from M \& B Taconic Ltd. Animal Suppliers (Ry, Denmark). Rats were maintained on a 12-h light/ dark cycle, at a constant temperature of $22^{\circ} \mathrm{C}$, and food and water were available ad libitum. For the validation of individual GK rats as a suitable animal model of human type 2 diabetes, non-fasting blood samples were taken from the tail vein of 12-week-old rats for measurement of glucose levels using the Accu Chek Advantage II system from Roche GmbH (Mannheim, Germany). Plasma insulin levels were determined in sodium heparin blood tubes from BD Biosciences (Nottingham, UK) employing a rat insulin ELISA test from Mercodia (Stockholm, Sweden). Tests were performed according to the manufacturer's instructions. GK rats $(11.24 \pm 0.51 \mathrm{mM}$ glucose; $n=33)$ showed a significant increase in glucose levels, as compared to agematched normal Wistar rats $(6.57 \pm 0.14 \mathrm{mM}$ glucose; $n=34$ ). In contrast, insulin levels were relatively comparable between both rat strains (GK rat: $0.37 \pm 0.06 \mu \mathrm{mol} / 1$ insulin, $n=33$; Normal rat: $0.36 \pm$ $0.07 \mu \mathrm{mol} / 1$ insulin, $n=31$ ). The average body weight of diabetic animals $(245.8 \pm 3.4 \mathrm{~g}, n=34)$ was slightly below that of normal rats $(257.4 \pm 3.8 \mathrm{~g}, n=34)$.

\section{Preparation of crude microsomal membranes}

Crude microsomal membranes were isolated from normal and GK skeletal muscle homogenates by an established subcellular fractionation method (Murray and Ohlendieck, 1997). To avoid proteolytic degradation of muscle proteins, all procedures were carried out at $4{ }^{\circ} \mathrm{C}$ in the presence of a protease inhibitor cocktail $(0.15 \mu \mathrm{M}$ aprotinin, $1 \mu \mathrm{M}$ leupeptin, $1.4 \mu \mathrm{M}$ pepstatin, $0.5 \mu \mathrm{M}$ soyabean trypsin inhibitor, $0.2 \mathrm{mM}$ pefabloc, $100 \mu \mathrm{M}$ PMSF, and $1 \mathrm{mM}$ EDTA). Protein concentration was determined according to Bradford (1976) and microsomal membrane vesicles were resuspended at a final protein concentration of $10 \mathrm{mg} / \mathrm{ml}$. Isolated membranes were used immediately for gel electrophoretic separation.

\section{Gel electrophoresis and immunoblot analysis}

Electrophoretic separation of microsomal proteins was carried out under reducing conditions using standard sodium dodecyl sulfate polyacrylamide gel electrophoresis (Dunn and Bradd, 1993). Employing a Mini-Protean MP3 electrophoresis system from BioRad Laboratories (Hemel Hempstead, Herts, UK), 7\% $(\mathrm{w} / \mathrm{v})$ resolving gels were used and $30 \mu \mathrm{g}$ protein loaded per lane. Electrophoretic transfer to nitrocellulose membranes was conducted at $100 \mathrm{~V}$ for $60 \mathrm{~min}$ according to Towbin et al. (1979). Incubation with antibodies and visualization of immuno-decorated protein bands was carried out by the enhanced ECL technique (Bradd and Dunn, 1993). Densitometric scanning of developed films was performed on an Epi Chemi II Geldoc UVP Image Analysis System, with Labworks 4.0 Image Acquisition \& Analysis Software (BioImaging Systems, Ultra Violet Products Ltd., Cambridge, UK). Statistical analyses were performed using Graphpad Prism 4.01 
(Graphpad Software, San Diego, CA). The unpaired Student's $t$-test was used to test for statistical significance. Blot overlay analysis with peroxidase-conjugated calsequestrin has been developed in our laboratory (Glover et al., 2002) and was carried out as previously described in detail (Mulvey and Ohlendieck, 2003).

\section{Two-dimensional gel electrophoretic analysis of crude muscle extracts}

To confirm the results from one-dimensional immunoblotting of microsomal membranes, two-dimensional immunoblotting with total skeletal muscle extracts was additionally performed. The preparation of muscle extracts for 2D gel electrophoresis has recently been optimized by our laboratory and described in detail (Dowling et al., 2004; Doran et al., 2004). Prior to isoelectric focussing, $1 \mathrm{~g}$ of skeletal muscle was snapfrozen in liquid nitrogen, ground to a fine powder, subjected to acetone washes and precipitation, and then solubilized in lysis buffer $(9.5 \mathrm{M}$ urea, $0.5 \%$ (v/v) ampholytes $\mathrm{pH} 3-10,4 \%$ (w/v) CHAPS, $100 \mathrm{mM}$ DTT). In order to prevent protein degradation, the solution was supplemented with a protease inhibitor cocktail, as described above. The samples were incubated at room temperature for $3 \mathrm{~h}$, centrifuged at $14,000 \mathrm{~g}$ for $20 \mathrm{~min}$ and then the supernatant diluted to a final protein concentration of $100 \mu \mathrm{g}$ per strip. Isoelectric focussing was performed using an IPGphor focussing system from Amersham Biosciences with 7-cm or 13-cm linear IPG strips of $\mathrm{pH} 3-10$. Following isoelectric focussing, proteins were separated in the second dimension by sodium dodecyl sulfate polyacrylamide gel electrophoresis (Froemming and Ohlendieck, 2001).

\section{Mass spectrometry-based proteomics analysis}

In order to carry out a comparative proteomics analysis of normal versus diabetic muscle fibres, the silver-stained 2D spot pattern of total protein extracts from normal versus diabetic muscle homogenates was quantified by densitometric scanning (Doran et al., 2004). Image analysis was performed with an Epi Chemi II Geldoc UVP Image Analysis System using Labworks 4.0 Image Acquisition and Analysis Software package (BioImaging System) for the evaluation of potential expression changes in candidate protein spots. Three separate control and three separate diabetic protein complement preparations were used to determine the fate of specific muscle protein species. As outlined above, statistical analyses were carried out with Graphpad Prism 4.01 (Graphpad Software), whereby the unpaired Student's $t$-test was employed to test for statistical significance. Gels were stored in $10 \%(\mathrm{v} / \mathrm{v})$ acetic acid for further analysis by mass spectrometry. 2D protein spots were excised from the slab gel using 1$\mathrm{ml}$ pipette tips and then transferred to Eppendorf tubes for destaining, chemical reduction and alkylation, as previously described in detail (Doran et al., 2004). For peptide fingerprinting of individual gel plugs, enzymatic digestion was initiated by the addition of trypsin. Following overnight digestion at $37^{\circ} \mathrm{C}$, tryptic fragments were mixed with a preparation of $\alpha$-cyano-4hydroxycinnamic acid and spotted onto the sample plates for MALDI-ToF mass spectrometric analysis. Angiotensin III $(897.5 \mathrm{~m} / \mathrm{z})$ and ACTH $(2465.19 \mathrm{~m} / \mathrm{z})$ were employed as internal standards of known peptide mass. An Amersham MALDI-ToF Pro instrument in the positive reflector mode with an accelerating voltage of $20 \mathrm{kV}$ and pulsed extraction was used for the recording of mass spectra, and Ettan MALDI Evaluation Software Version 2 from Amersham Biosciences was employed for mass spectra analysis. Protein identification using the generated peptide mass fingerprint was then achieved with the PMF Pro-Found search engine and the NR database. Predicted pI and $\mathrm{kDa}$ values for each identified protein, as well as percent sequence coverage by the digestion-generated peptides, were provided by the software programme. All positive protein hits generated by Amersham Biosciences MALDI evaluation software were matched against the publicly available search engine MASCOT (http:// www.matrixscience.com).

\section{Subcellular fractionation by sucrose gradient density centrifugation}

Subcellular muscle fractions were isolated by a centrifugation method adapted from Garvey et al. (1998). This method is a modification of that previously used to demonstrate insulin-mediated translocation of glucose transporters in rat muscle (Klip et al., 1987). All preparative steps were conducted at $4{ }^{\circ} \mathrm{C}$ in the presence of a protease inhibitor cocktail. Crude skeletal microsomal membranes ( $80 \mathrm{mg}$ protein) were carefully layered on top of a discontinuous sucrose tri-layer of $25 \%(\mathrm{w} / \mathrm{v})$, $28 \%(\mathrm{w} / \mathrm{v})$ and $32 \%(\mathrm{w} / \mathrm{v})$ sucrose solution containing $25 \mathrm{mM}$ HEPES (pH 7.5) and $1 \mathrm{mM}$ EGTA. The gradient was centrifuged at $150,000 \mathrm{~g}$ for $16 \mathrm{~h}$ in a swinging bucket SW32 rotor at $4{ }^{\circ} \mathrm{C}$ using an Optima L-100 XP Ultracentrifuge from Beckman Coulter (Palo Alto, CA, USA) to achieve sufficient separation of subcellular membrane fractions. Well-defined bands were visible at the interfaces between each layer, with the $25 \%$ and $32 \%$ bands representing crude fractions derived from the surface membranes and intracellular membranes, respectively. Individual membrane fractions and the pellet fraction were collected, washed by 5 -fold dilution in the above-mentioned HEPES buffer and then pelleted 
by centrifugation at $190,000 \mathrm{~g}$ for $90 \mathrm{~min}$ employing a Beckman Ti70 rotor. The resulting subcellular fraction pellets were resuspended in HEPES buffer and immediately used for electrophoretic separation and subsequent immunoblot analysis.

\section{Immunofluorescence microscopy and histochemical staining}

Tissue preparation, cryo-sectioning and antibody incubation were performed as previously described in detail (Culligan et al., 2002). Transverse sections of $12 \mu \mathrm{m}$ thickness were prepared using a standard cryostat from Microm (Heidelberg, Germany) and mounted on Superfrost Plus positively charged microscope slides (Menzel Gläser, Braunschweig, Germany). Following fixation and blocking, muscle sections were incubated with primary and fluorescein- or rhodamine-conjugated secondary antibodies. Fluorescent images were viewed with an AxioCam HRc microscope from Carl Zeiss Vision GmbH (Munich, Germany) and recorded with a digital camera using Axiovision 4 image acquisition software. Haematoxylin and eosin (H\&E) staining of tissue sections, labelling of nuclei with DAPI, and histochemical staining for succinate dehydrogenase and NADPH diaphorase were performed by standard procedures (Kameya et al., 1999; Yasuda et al., 2002; Dowling et al., 2004).

\section{Results}

Insulin resistance in skeletal muscle is an extremely important feature of type 2 diabetes (Petersen and Shulman, 2002). Here, we have used the non-obese GK rat model to determine potential abnormalities in diabetic skeletal muscle fibres. Following the initial discovery that the expression of the sarcolemmal glycoprotein $\beta$-dystroglycan is affected in GK skeletal muscle, the biochemical and cell biological status of important dystroglycan-associated proteins was determined.

\section{Abnormal subcellular localization of glucose transporter in diabetic GK skeletal muscle}

As illustrated in the Coomassie-stained gel (Fig. 1A), the overall protein composition of normal and GK microsomes from skeletal muscle is relatively comparable. Immunoblotting with antibodies to the insulin receptor, the IRS1, the growth factor receptor-bound protein Grb2 and the muscle glucose transporter isoform GLUT4 (Fig. 1B-E) revealed no statistically significant differences in their expression levels between control and diabetic specimens (Fig. 1F-I). Following
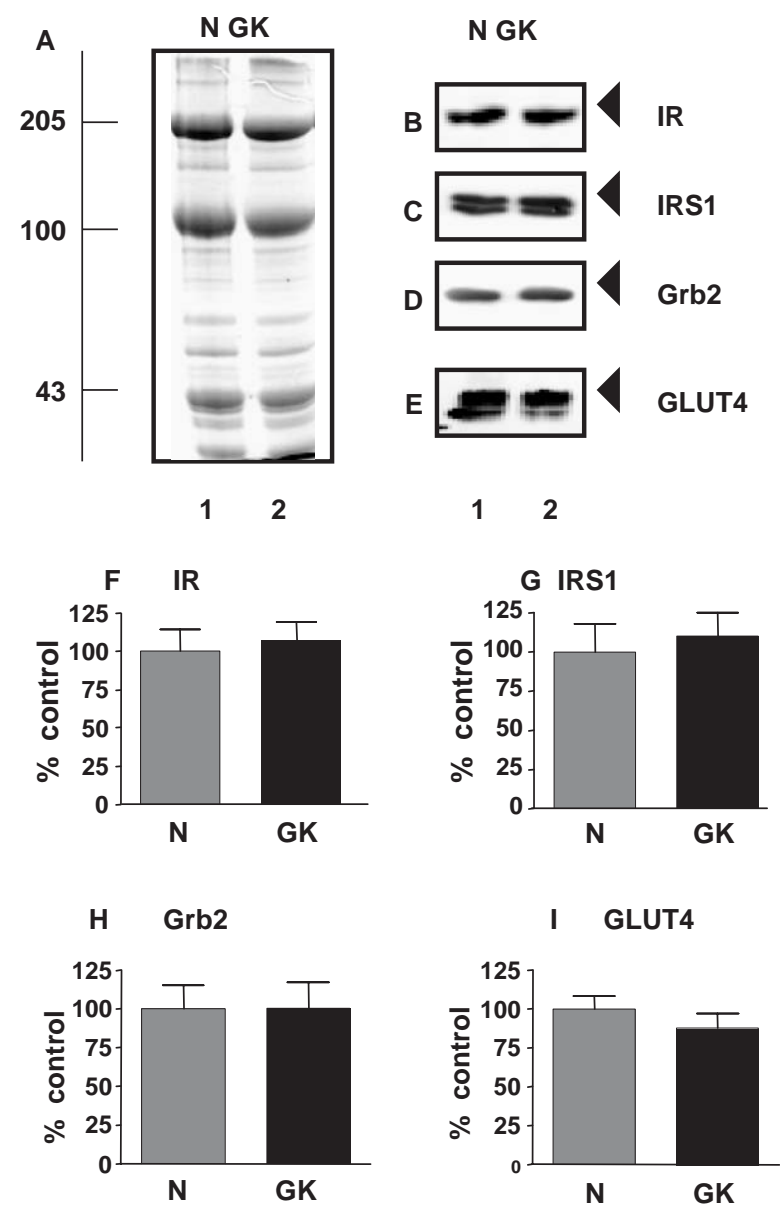

Fig. 1. Immunoblot analysis of the insulin receptor and glucose transporter in GK skeletal muscle microsomes. Coomassie-stained gel (A) and identical immunoblots (B-E) labelled with antibodies to the insulin receptor (B; IR), the insulin receptor substrate (C; IRS1); the growth factor receptor-bound protein 2 (D, Grb2), and the glucose transporter (E; GLUT4). (F-I) Graphical presentation of the immunoblot analysis $(n=15$; no significant differences; unpaired $t$-test). Lanes 1 and 2 represent membranes from normal control muscle $(\mathrm{N})$ and diabetic Goto-Kakizaki muscle (GK), respectively. Molecular mass standards (in $\mathrm{kDa}$ ) are indicated on the left. The positions of immunodecorated proteins are marked by arrowheads.

this initial analysis of the abundance of key regulators of glucose metabolism, the subcellular location of the main muscle glucose transporter was determined by sucrose gradient centrifugation. For standardization, the distribution of markers of the sarcolemma, the transverse tubules and the sarcoplasmic reticulum in the various fractions were determined. The surface $\mathrm{Na}^{+} / \mathrm{K}^{+}$-ATPase was mostly found in the lightest membrane fraction at the top of the sucrose density gradient (Fig. 2A), the $\alpha_{1 \mathrm{~s}}$-subunit of the dihydropyridine receptor was enriched in the $25 \%$ to $32 \%$ sucrose fractions (Fig. 2B) and the terminal cisternae component calsequestrin was 
present in all fractions (Fig. 2C). Although the highly abundant sarcoplasmic reticulum membranes appear to cross-contaminate lighter fractions, the immuno-decoration of marker proteins demonstrated an overall successful fractionation between lighter and heavier membrane fractions. In contrast to normal muscle, which showed an association of the GLUT4 isoform

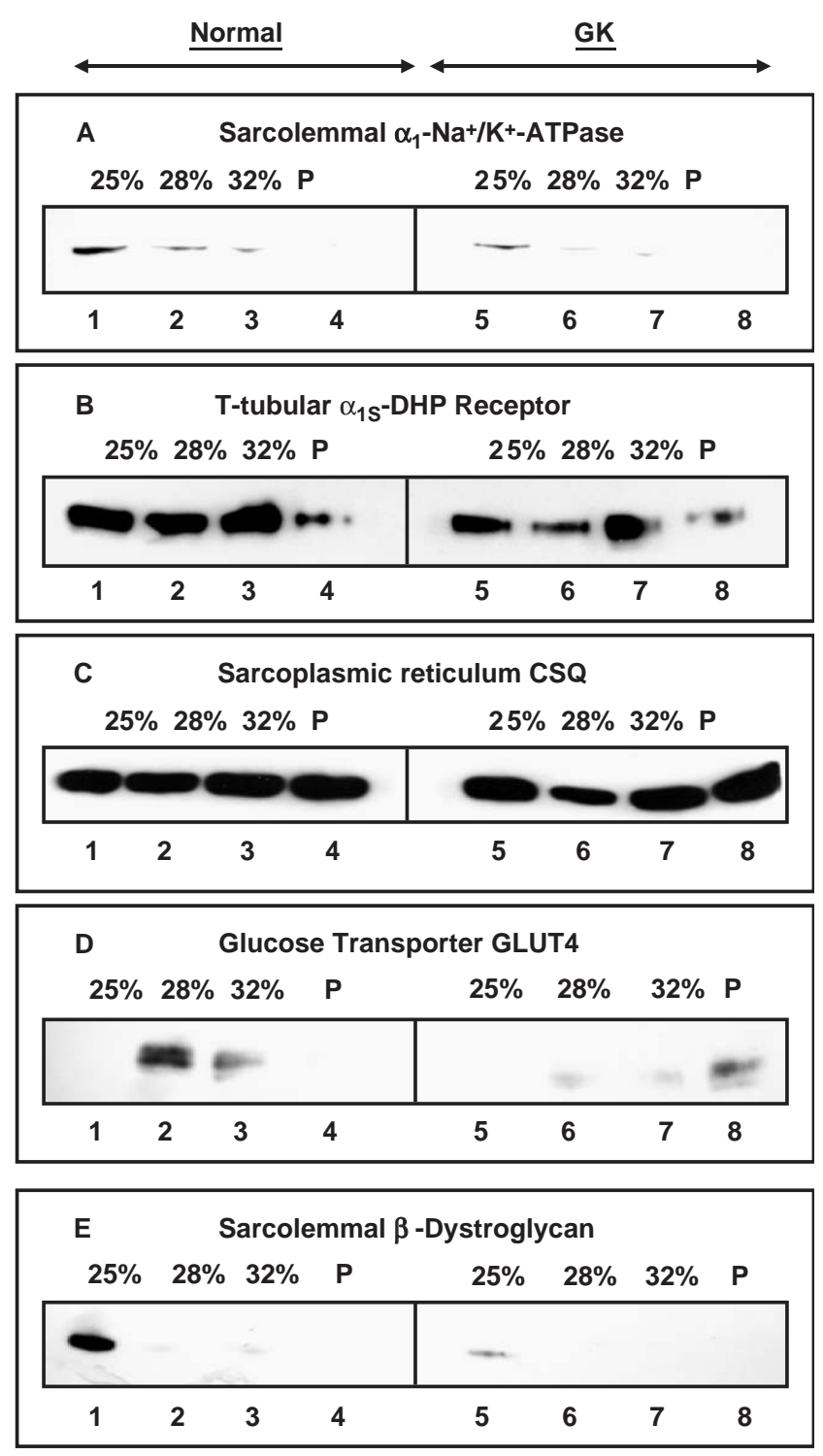

Fig. 2. Subcellular fractionation analysis of glucose transporter GLUT4 in GK skeletal muscle. Identical immunoblots labelled with antibodies to the $\alpha_{1}$-subunit of the $\mathrm{Na}^{+} / \mathrm{K}^{+}$ATPase (A), the $\alpha_{1 \mathrm{~S}}$-subunit of the dihydropyridine receptor (B; DHP), calsequestrin (C; CSQ), the glucose transporter (D; GLUT4), and $\beta$-dystroglycan (E). Lanes $1-4$ and lanes 5-8 represent membranes from normal control muscle and diabetic Goto-Kakizaki muscle (GK), respectively. Fractions were prepared by sucrose density gradient centrifugation and correlate to a $25 \%, 28 \%$ and $32 \%(\mathrm{w} / \mathrm{v})$ sucrose concentration and the pellet $(\mathrm{P})$. with lighter membrane fractions representing surface and internal membranes, the glucose transporter was found in GK muscle in a heavier membrane fraction (Fig. 2D). This finding indicates an abnormal location of GLUT4 in basal, non-insulin-stimulated diabetic GK muscle. However, the most interesting result taken from this immunoblot analysis was the observation that the expression of another surface membrane marker, the 43$\mathrm{kDa}$ sarcolemmal glycoprotein named $\beta$-dystroglycan, was drastically reduced (Fig. 2E). Since dystroglycans form an important complex that indirectly links the cortical cytoskeleton to the extracellular matrix, we initiated a comprehensive immunoblotting survey of dystroglycan-associated muscle components.

\section{Reduced expression of the dystrophin-dystroglycan complex in diabetic GK skeletal muscle}

The central elements of the surface membrane that associate with $\beta$-dystroglycan are the membrane cytoskeletal protein dystrophin of $427 \mathrm{kDa}$ on the cytoplasmic side and $\alpha$-dystroglycan of $156 \mathrm{kDa}$ on the extracellular side. Both muscle proteins interact with a range of other surface elements, such as laminin, sarcoglycans, dystrobrevins and syntrophins. Immunodecoration of nitrocellulose replicas of gels with equally loaded lanes (Fig. 3A) showed a drastic reduction in the expression of the full-length dystrophin isoform Dp427 (Fig. 3C) and both dystroglycans (Fig. 3D, E). In contrast, the $\alpha$ dystroglycan binding partner laminin (Fig. 3B) and the dystrophin-associated proteins $\alpha$-sarcoglycan, $\delta$-sarcoglycan and $\alpha$-dystrobrevin (Fig. $3 \mathrm{~F}-\mathrm{H}$ ) were shown not to be affected in the GK muscle. For control purposes, the immunoblotting of the surface membrane marker $\mathrm{Na}^{+} / \mathrm{K}^{+}$-ATPase is shown in Fig. 3I. The statistical analysis of our immunoblotting survey is illustrated in the bar diagrams of Fig. 3J-Q demonstrating the significant reduction of dystrophin and $\alpha / \beta$-dystroglycans in diabetic muscle.

\section{Reduction in the syntrophin-associated neuronal isoform of nitric oxide synthase in diabetic GK skeletal muscle}

An important signalling enzyme that is associated with the muscle dystrophin-glycoprotein complex via syntrophin is the neuronal nitric oxide synthase isoform nNOS. Interestingly, both the expression of $\alpha$-syntrophin and nNOS was found to be considerably less in diabetic GK preparations as compared to control muscle (Fig. 4A, B, D, E). In contrast, immunoblotting with an antibody to the protein product of the house-keeping gene that encodes the glyceraldehyde-3-phosphate dehydrogenase, showed a very comparable level of this marker (Fig. 4C, F). The reduction in nNOS was confirmed by a standard histochemical 

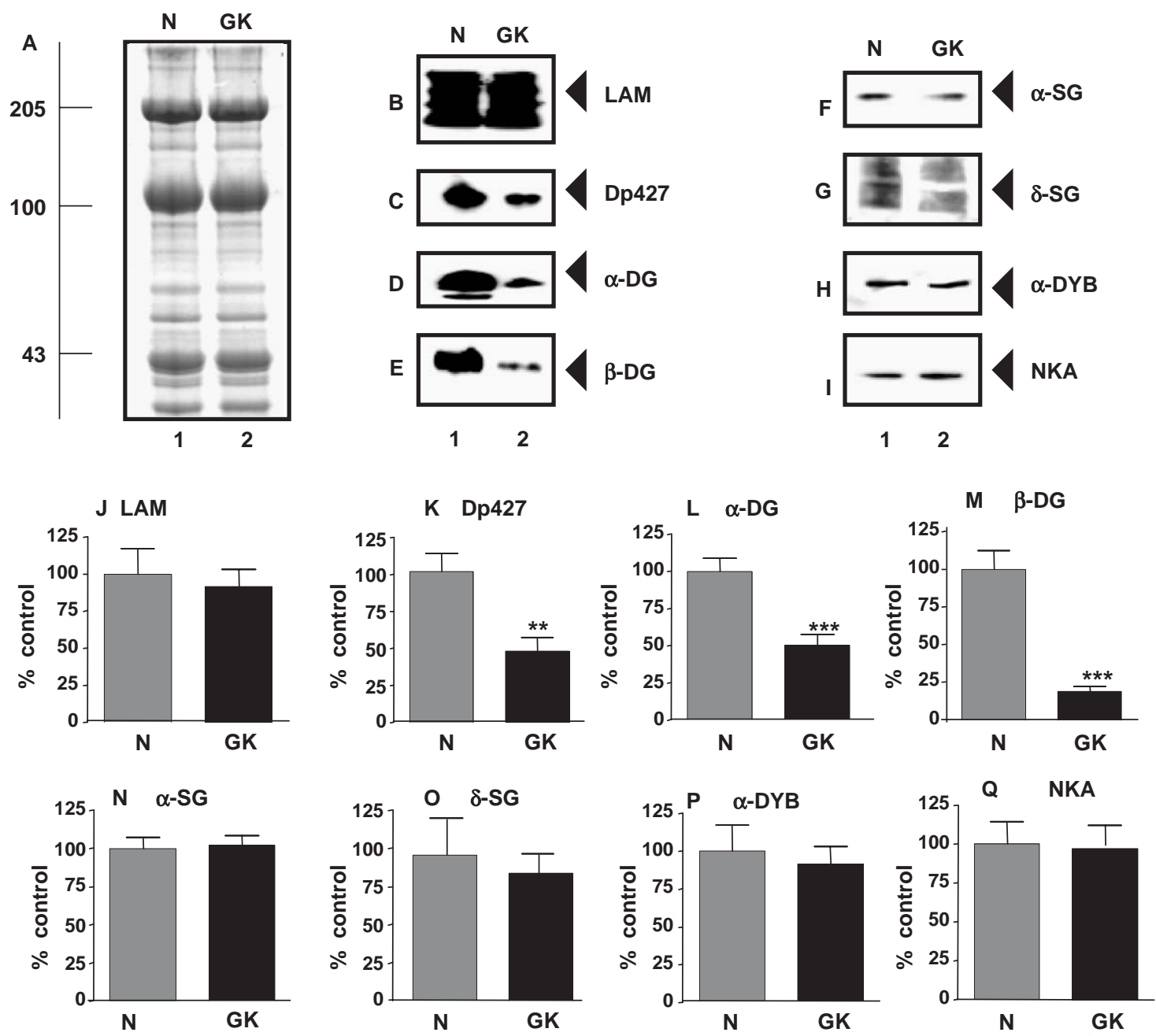

Fig. 3. Immunoblot analysis of dystrophin-associated glycoproteins in GK skeletal muscle. Coomassie-stained gel (A) and identical immunoblots (B-I) labelled with antibodies to laminin (B; LAM), the full-length dystrophin isoform of $427 \mathrm{kDa}(\mathrm{C}$; Dp427), $\alpha$ dystroglycan (D; $\alpha$-DG), $\beta$-dystroglycan (E; $\beta$-DG), $\alpha$-sarcoglycan $(\mathrm{F} ; \alpha$-SG), $\delta$-sarcoglycan $(\mathrm{G} ; \delta$-SG), $\alpha$-dystrobrevin $(\mathrm{H} ; \alpha$-DYB), and the $\alpha_{1}$-subunit of the $\mathrm{Na}^{+} / \mathrm{K}^{+}$-ATPase (I; NKA). (J-Q) Graphical presentation of the immunoblot analysis $\left(n=15\right.$; ${ }^{* *} p<0.01$; ${ }^{* * *} p<0.001$; unpaired $t$-test). Lanes 1 and 2 represent membranes from normal control muscle (N) and diabetic Goto-Kakizaki muscle (GK), respectively. Molecular mass standards (in kDa) are indicated on the left. The positions of immuno-decorated proteins are marked by arrowheads.

analysis of transverse muscle sections. The staining pattern showed nitric oxide synthases to be down-regulated in diabetic tissue (Fig. 4G, H). Although this crude histochemical staining procedure does not differentiate between different NOS isoforms, it gives a good indication that the expression levels of this group of enzymes are affected in diabetes. Obviously, the result from immunoblotting is a more reliable indicator with respect to isoform-specific changes in NOS expression levels.

\section{Status of excitation-contraction coupling and muscle relaxation elements in diabetic GK skeletal muscle}

Since abnormal $\mathrm{Ca}^{2+}$ handling and impaired regulation of the excitation-contraction-relaxation cycle is implicated in secondary changes leading to skeletal muscle fibre degeneration, we have investigated the status of key ion-regulatory elements in diabetic fibres. The main protein species involved in the regulation of neuronal transmission, voltage sensing, $\mathrm{Ca}^{2+}$ release, $\mathrm{Ca}^{2+}$ binding, endogenous receptor modulation and $\mathrm{Ca}^{2+}$ uptake are represented by the nicotinic acetylcholine receptor of the post-synaptic muscle surface membrane, the $\alpha_{1 \mathrm{~s}}$-dihydropyridine receptor of the transverse tubules, the ryanodine receptor $\mathrm{Ca}^{2+}$ release channel complex of the triad junctions, calsequestrin and calsequestrin-like proteins of the terminal cisternae region and the SERCA-type $\mathrm{Ca}^{2+}$-ATPases. In analogy to the comparable expression levels of major protein species in normal versus diabetic fibres (Fig. 5A), no major changes in the abundance of these six central 

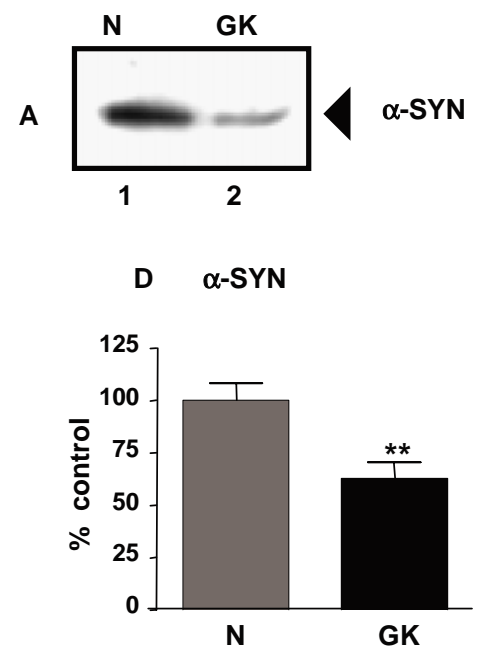

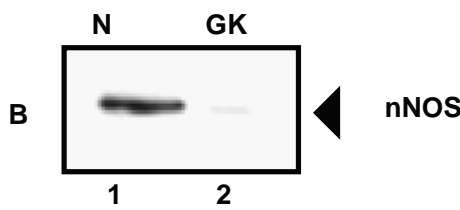

E nNOS

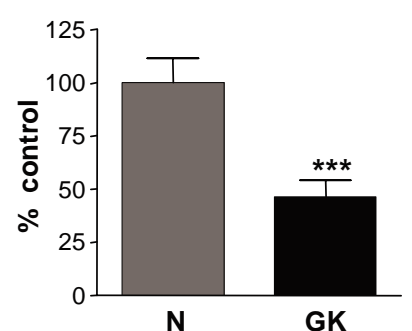

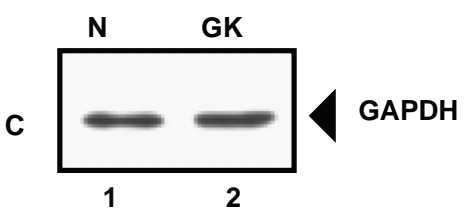

F GAPDH

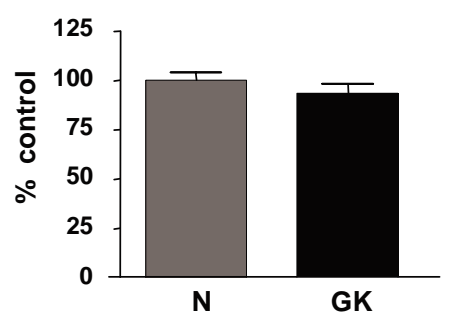

G Control NOS

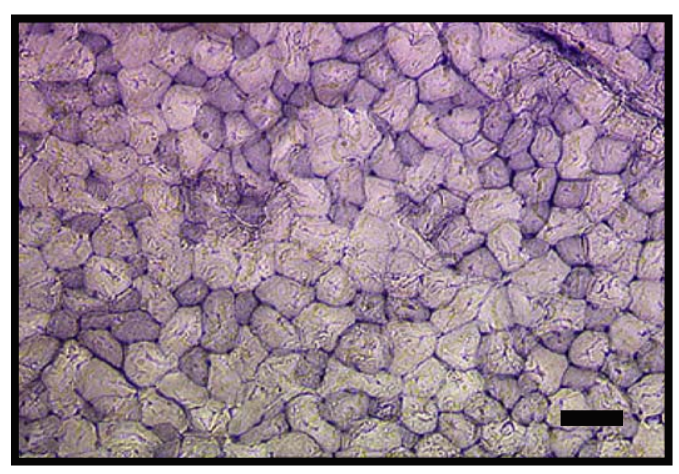

H GK NOS

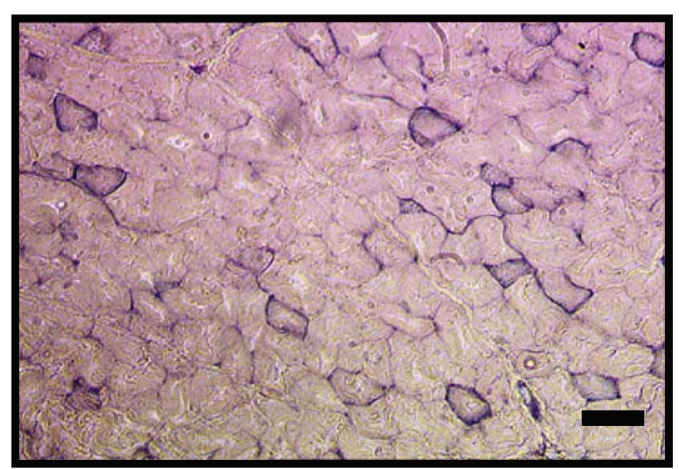

Fig. 4. Status of the syntrophin-associated nitric oxide synthase in GK skeletal muscle. Identical immunoblots labelled with antibodies to $\alpha$-syntrophin (A; $\alpha$-SYN), the neuronal isoform of nitric oxide synthase (B; nNOS), and glyceraldehyde-3-phosphate dehydrogenase (C; GAPDH). Transverse muscle sections that have been histochemically stained for nitric oxide synthase activity are shown in $(\mathrm{G}, \mathrm{H})$. Bars $=40 \mu \mathrm{m}$. (D-F) Graphical presentation of the immunoblot analysis $\left(n=15 ;{ }^{* *} p<0.01 ;{ }^{* * *} p<0.001 ;\right.$ unpaired $t$-test). Lanes 1 and 2 represent membranes from normal control muscle (N) and diabetic Goto-Kakizaki muscle (GK), respectively. The positions of immuno-decorated proteins are marked by arrowheads.

regulators of excitation-contraction coupling and muscle relaxation were observed (Fig. 5B-F, H-M). Reduction in the expression of calsequestrin-like proteins is an established feature of dystrophin-deficient muscle fibres, such as the MDX animal model of Duchenne muscular dystrophy (Culligan et al., 2002). The comparative immuno-decoration of GK versus MDX microsomes with monoclonal antibody $\mathrm{VIIID}_{2}$ to calsequestrin clearly established the preserved status of these luminal $\mathrm{Ca}^{2+}$-binding proteins in diabetic fibres (Fig. 5F, L, M), but their drastic reduction in MDX preparations (Fig. 5G, N, O). It has previously been shown that muscle degeneration has an effect on protein-protein interactions within the triadic membrane assembly (Glover et al., 2002). In order to determine potential differences between normal and diabetic muscle fibres, we performed a blot overlay assay with a peroxidaseconjugated calsequestrin probe. Using electrophoretically separated normal and GK preparations (Fig. 5P), the calsequestrin probe was found to bind to itself, the ryanodine receptor, calsequestrin-like proteins and junctin (Fig. 5R). This binding pattern agreed with our previous overlay analysis and showed no differences in the protein-protein interaction between excitation-contraction elements in normal versus GK fibres. The immunoblot of Fig. 5Q shows the relative position of the calsequestrin monomer of apparent $63 \mathrm{kDa}$ and the CLPs of higher molecular mass. Thus, although the expression of the dystrophin-dystroglycan complex is reduced in GK muscle, this destabilising effect on the sarcolemma does not appear to have a direct effect on the expression levels and oligomeric status of ionregulatory components.

\section{Mass spectrometry-based proteomics analysis of normal versus diabetic GK skeletal muscle}

In order to determine whether the diabetic GK phenotype is associated with major changes in the 

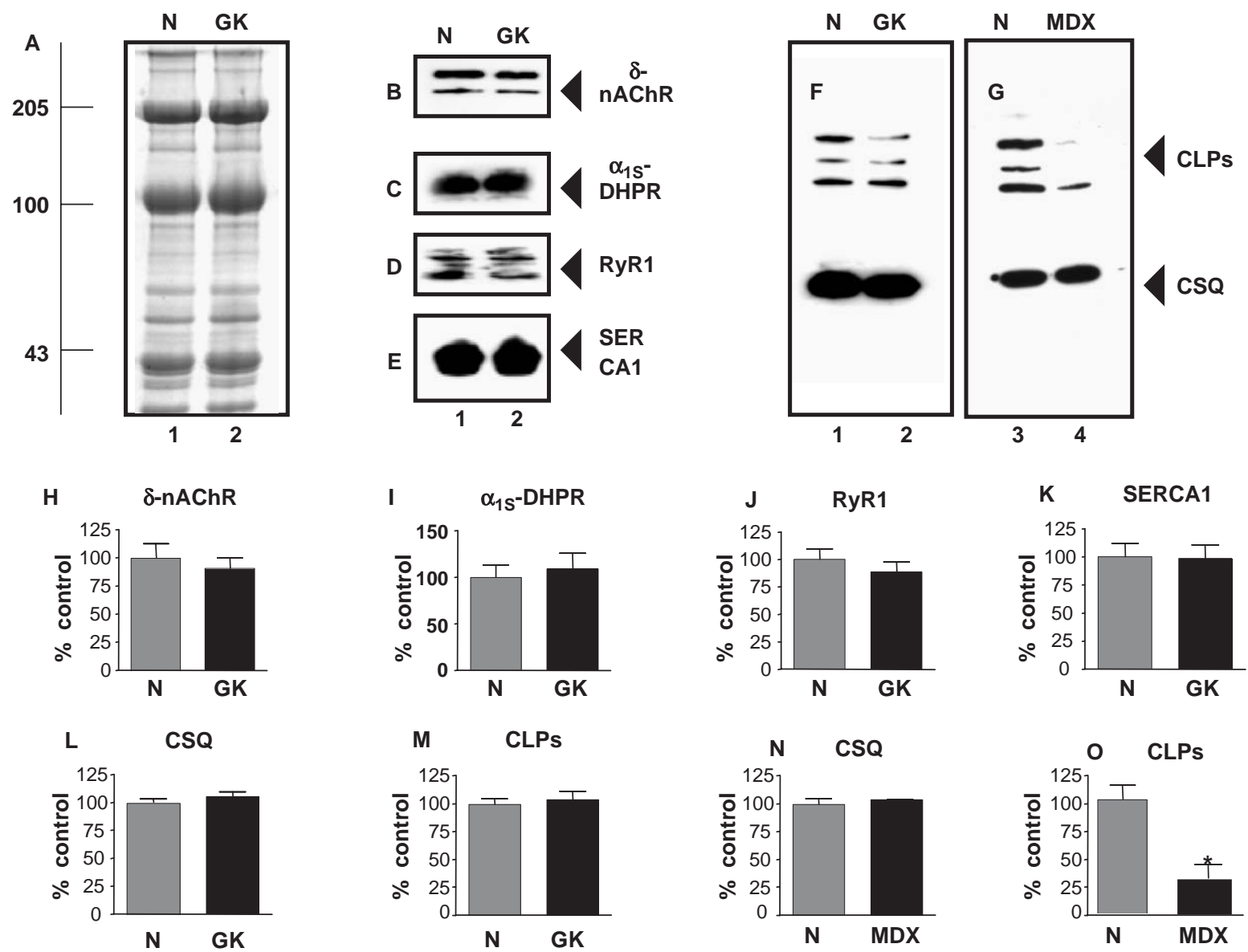

P CB

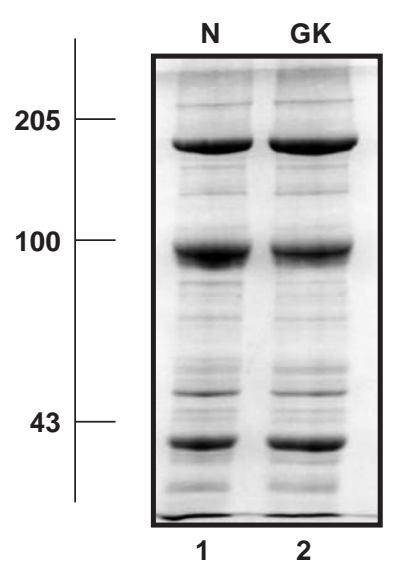

Q CSQ-IB

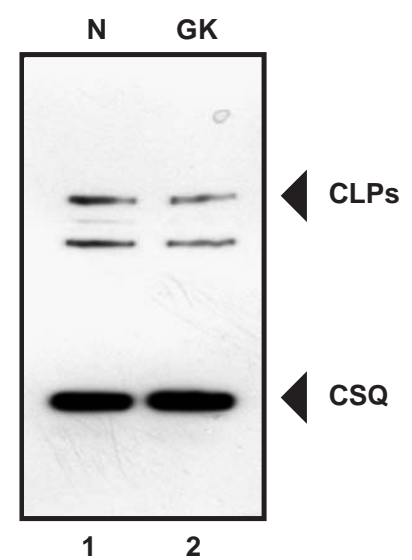

R CSQ-OL

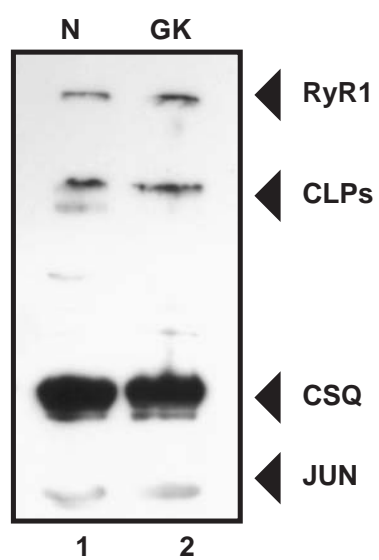

Fig. 5. Immunoblot analysis of excitation-contraction-relaxation cycle elements in GK muscle. Coomassie-stained gels (A, P) and immunoblots (B-G; Q) labelled with antibodies to the $\delta$-subunit of the nicotinic acetylcholine receptor $\left(\mathrm{B}\right.$; $\delta$-nAChR), the $\alpha_{1 \mathrm{~S}^{-}}$ subunit of the dihydropyridine receptor $\left(\mathrm{C} ; \alpha_{1 \mathrm{~S}}\right.$-DHPR), the ryanodine receptor $\mathrm{Ca}^{2+}$-release channel (D; RyR1), the fast isoform of the sarcoplasmic reticulum $\mathrm{Ca}^{2+}$ ATPase (E; SERCA1), calsequestrin (F, G, Q; CSQ) and calsequestrin-like proteins (F, G, Q; CLPs). A calsequestrin blot overlay is shown in $(\mathrm{R})$. (H-O) Graphical presentation of the immunoblot analysis $\left(n=15 ;{ }^{*} p<0.05\right.$; unpaired $t$-test). Lanes 1 and 2 represent membranes from normal control muscle $(\mathrm{N})$ and diabetic Goto-Kakizaki muscle (GK), respectively. For comparative purposes, lanes 3 and 4 in $(G)$ show membranes from control and dystrophic MDX muscle. Molecular mass standards (in $\mathrm{kDa}$ ) are indicated on the left. The positions of immuno-decorated proteins are marked by arrowheads. (P-R) Blot overlay (OL) analysis of normal and diabetic GK membranes with a peroxidase-conjugated calsequestrin probe. The relative position of calsequestrin and calsequestrin-like proteins is illustrated by immunoblotting (IB), and the labelled bands representing the ryanodine receptor (RyR1), calsequestrin (CSQ), calsequestrin-like proteins (CLPs), and junctin (JUN) are marked by arrowheads in (R). 
expression profile of key muscle protein species, densitometric scans of the electrophoretically-separated normal versus GK protein complement were evaluated with $2 \mathrm{D}$ analysis software. As outlined in a previous proteomics survey of dystrophic skeletal muscle, twodimensional gel electrophoresis methodology is hampered by a range of technical problems (Doran et al., 2004). Limitations of protein staining, incomplete transfers and the combination of isoelectric focussing and standard polyacrylamide gel electrophoresis may cause an under-representation of certain protein species, such as low-abundance proteins, highly acidic or basic proteins, integral membrane proteins and very highmolecular-mass proteins. Therefore, the $2 \mathrm{D}$ spot pattern shown in Fig. 6A, B is not representative of the complete protein repertoire of normal and diabetic skeletal muscle. However, despite these technical problems, two-dimensional gel electrophoresis is still an unparalleled technique for the proper separation of a wide range of proteins with varying isolectric point and molecular mass. The 2D gels shown here have separated a broad range of high-abundance muscle components including the contractile apparatus and various key enzyme systems. The numbering of major protein spots in the silver-stained gels highlights established muscle marker proteins, which could be identified by mass spectrometry (Fig. 6A, B). Spots 1-11 were identified by mass spectrometric analysis as enolase- $3 \beta$, aldolase-A, tropomyosin- $2 \beta$, creatine kinase, GAPDH-like protein, tropomyosin- $1 \alpha$, thymidine kinase, myosin light chain-1, adenylate kinase-1, myosin light chain-2, and parvalbumin, respectively. See Table 1 for results from the mass spectra analysis of identified muscle proteins. The densitometric analysis of the 11 proteins did not reveal a statistically significant difference in their expression levels between control and GK specimens. Importantly, since adenylate kinase was recently shown to be greatly reduced in dystrophin-deficient MDX preparations (Ge et al., 2003), the persistent expression of this metabolic enzyme indicates a lack of dystrophic pathology in GK muscle. Overall, the proteomics screening of the GK protein complement showed no major differences in the protein expression profile as compared to normal muscle.

\section{Two-dimensional gel electrophoretic analysis of dystrophin-associated glycoproteins in diabetic GK skeletal muscle}

Differential centrifugation of tissue homogenates may introduce artefacts during subcellular fractionation steps that can potentially lead to the overestimation or underestimation of the density of protein species with respect to the total muscle protein complement. We have therefore also employed comparative $2 \mathrm{D}$ immunoblot- ting of total crude muscle extracts. However, many antibodies are not specific enough to properly recognize low abundance epitopes in crude muscle preparations. In addition, large proteins, such as dystrophin $(427 \mathrm{kDa})$ or the ryanodine receptor $(565 \mathrm{kDa})$ do not properly transfer from the isoelectric focussing strips into the second slab gel dimension and can therefore not be analysed by this technique. Nevertheless, a subset of antibodies was able to detect specific proteins following 2D separation and confirmed the results from the 1D analysis of microsomes. The silver-stained gels of Fig. $6 \mathrm{~A}, \mathrm{~B}$, used for mass spectrometric analyses as described above, illustrate the relatively comparable overall protein expression pattern of normal versus diabetic GK muscle fibres. A more detailed proteomics approach, using the novel fluorescence difference gel electrophoresis technique, suggests itself for identifying potential minor changes in the protein expression profile by mass spectrometry and will be attempted in future studies. 2D immunoblotting revealed no major differences in the expression of the fast SERCA1 isoform of the sarcoplasmic reticulum $\mathrm{Ca}^{2+}$-ATPase, glyceraldehyde-3-phosphate dehydrogenase, the insulin receptor, the IRS1 and the adaptor molecule Grb2 between normal and diabetic extracts (Fig. 6C-H). In contrast, the abundance of the dystrophin-associated proteins $\alpha$ dystroglycan, $\beta$-dystroglycan, $\alpha$-syntrophin and the enzyme nNOS were found to be reduced in total GK muscle preparations as compared to unaffected control tissue (Fig. 6I-L). This agrees with 1D immunoblot analyses in Figs. 1, 3, 4 and 5. The immunoblotting image shown in Fig. 6D shows the entire 2D blot region and illustrates the lack of low-molecular-mass fragments of the $110 \mathrm{kDa} \mathrm{Ca}{ }^{2+}$ pump. In agreement with the preserved protein expression pattern of the GK protein complement, as shown above by mass spectrometrybased proteomics, this finding also suggests a lack of major skeletal muscle pathology in the GK rat model of type 2 diabetes.

\section{Drastic reduction of dystrophin and $\alpha / \beta$ - dystroglycans in diabetic GK skeletal muscle fibres as revealed by immunofluorescence microscopy}

Indirect immunofluorescence microscopy was employed to study the effect of diabetes on the localization of dystrophin and dystroglycans in skeletal muscle fibres. Transverse cryosections, the cellular structure of which was preserved as shown in the eosin-stained panels of Fig. 7A, B, were immuno-decorated with monoclonal antibodies to the proteins that constitute the backbone of the dystrophin-glycoprotein complex. Surface labelling for dystrophin, $\alpha$-dystroglycan and $\beta$ dystroglycan revealed a greatly reduced expression in the majority of diabetic cells (Fig. 7C-H). While normal 

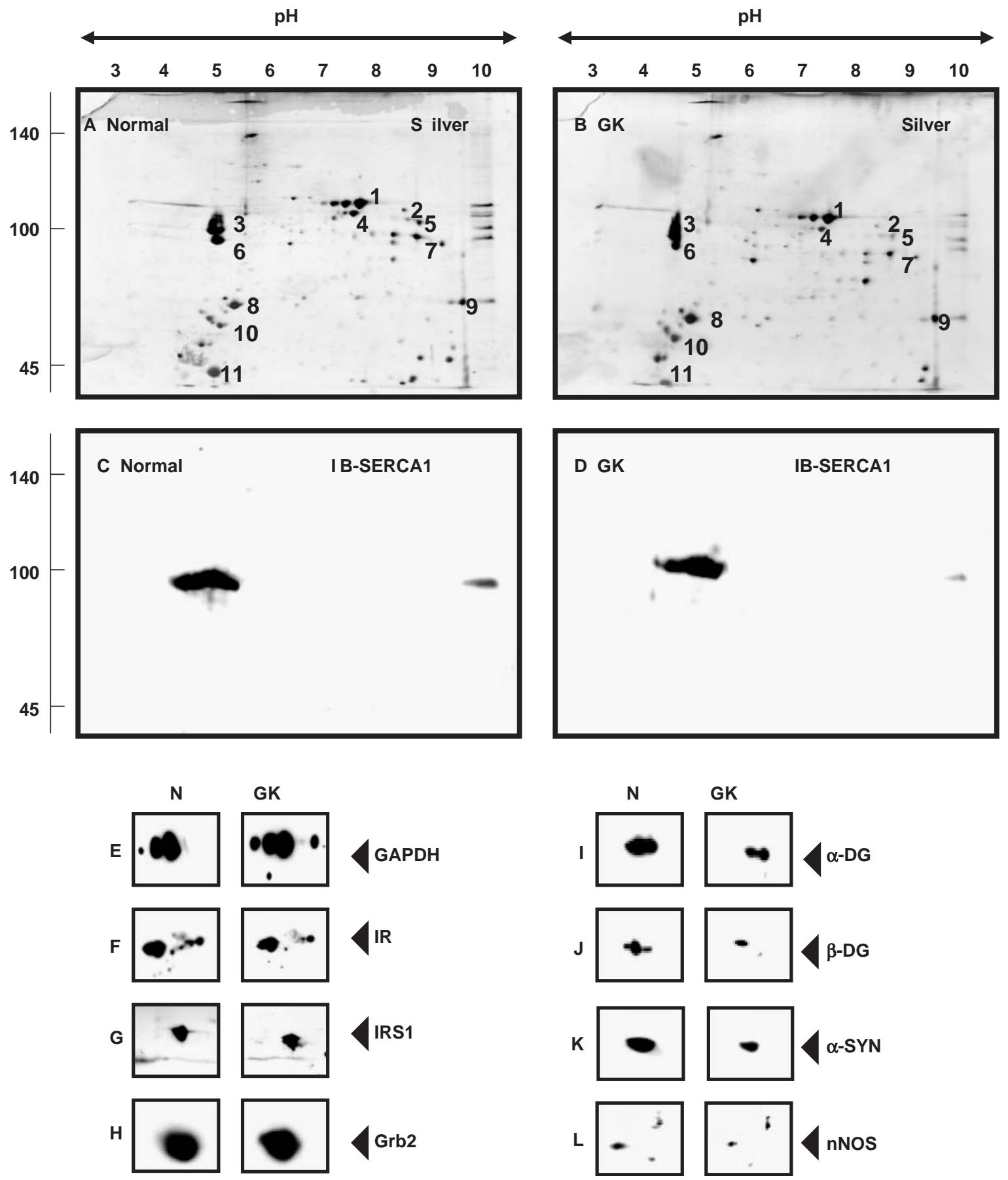

Grb2

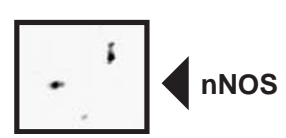

Fig. 6. Two-dimensional gel electrophoretic analysis of total GK skeletal muscle extracts. Crude total muscle extracts from normal and GK fibres were separated in the first dimension by isolelectric focussing and in the second dimension by sodium dodecyl sulfate polyacrylamide gel electrophoresis. Silver-stained gels of normal (A) and diabetic (B; GK) preparations. (C-L) Identical immunoblots. The protein species represented by the 11 main $2 \mathrm{D}$ spots in these gels were clearly identified by mass spectrometric analysis as enolase- $3 \beta$, aldolase-A, tropomyosin- $2 \beta$, creatine kinase, GAPDH-like protein, tropomyosin- $1 \alpha$, thymidine kinase, myosin light chain-1, adenylate kinase-1, myosin light chain-2, and parvalbumin, respectively. The results from the mass spectra analysis and Swiss-Prot Accession numbers of identified muscle proteins is listed in Table 1. (C, D) 2D immunoblots (IB) labelled with an antibody to the fast isoform of the sarcoplasmic reticulum $\mathrm{Ca}^{2+}$ ATPase (SERCA1), demonstrating the lack of lowmolecular-mass degradation products in total GK muscle preparations (D). The additional immunoblotting panels (E-L) focus on the area of the antibody-decorated protein spots. Nitrocellulose replicas were labelled with antibodies to glyceraldehyde-3phosphate dehydrogenase (E; GAPDH), the insulin receptor (F; IR), the insulin receptor substrate (G; IRS1), the growth factor receptor-bound element $(\mathrm{H} ; \mathrm{Grb} 2), \alpha$-dystroglycan $(\mathrm{I} ; \alpha$-DG), $\beta$-dystroglycan $(\mathrm{J} ; \beta$-DG), $\alpha$-syntrophin $(\mathrm{K} ; \alpha$-SYN), and the neuronal isoform of nitric oxide synthase ( $\mathrm{L}$; nNOS). The $\mathrm{pH}$ values of the first dimension gel system and molecular mass standards (in $\mathrm{kDa}$ ) of the second dimension are indicated on the top and on the left of panels (A)-(D), respectively. The positions of immuno-decorated proteins are marked by arrowheads. 
Table 1. Representative protein species identified in normal and diabetic skeletal muscle extracts by mass spectrometry-based proteomics

\begin{tabular}{|c|c|c|c|c|c|}
\hline Spot No. & Protein & Sequence coverage $(\%)$ & Molecular mass (kDa) & Isoelectric point pI & SwissProt Acc. No \\
\hline 1 & Enolase $3 \beta$ & 41.9 & 47.35 & 6.7 & $\mathrm{P} 21550$ \\
\hline 2 & Aldolase A & 28.8 & 39.79 & 8.8 & P05064 \\
\hline 3 & Tropomyosin $2 \beta$ & 25.7 & 32.93 & 4.7 & P07951 \\
\hline 4 & Creatine kinase & 36.5 & 43.23 & 6.6 & P07310 \\
\hline 5 & GAPDH-like protein & 19.2 & 36.05 & 8.7 & P16858 \\
\hline 6 & Tropomyosin $1 \alpha$ & 50.0 & 32.75 & 4.7 & P58771 \\
\hline 7 & Thymidine kinase & 25.1 & 28.99 & 9.5 & P27158 \\
\hline 8 & Myosin light chain 1 & 73.5 & 20.78 & 5.0 & P05977 \\
\hline 9 & Adenylate kinase 1 & 29.9 & 21.68 & 7.8 & P39069 \\
\hline 10 & Myosin light chain 2 & 60.0 & 19.12 & 4.8 & P97457 \\
\hline 11 & Parvalbumin & 30.3 & 11.78 & 5.0 & P32848 \\
\hline
\end{tabular}

All positive protein hits generated by Ettan MALDI Evaluation Software Version 2 (Amersham Biosciences) were matched against the publicly available search engine MASCOT (http://www.matrixscience.com). The densitometric analysis of the listed protein spots from 2D gels representing normal muscle versus diabetic muscle did not reveal a statistically significant difference in expression levels between control and GK specimens.
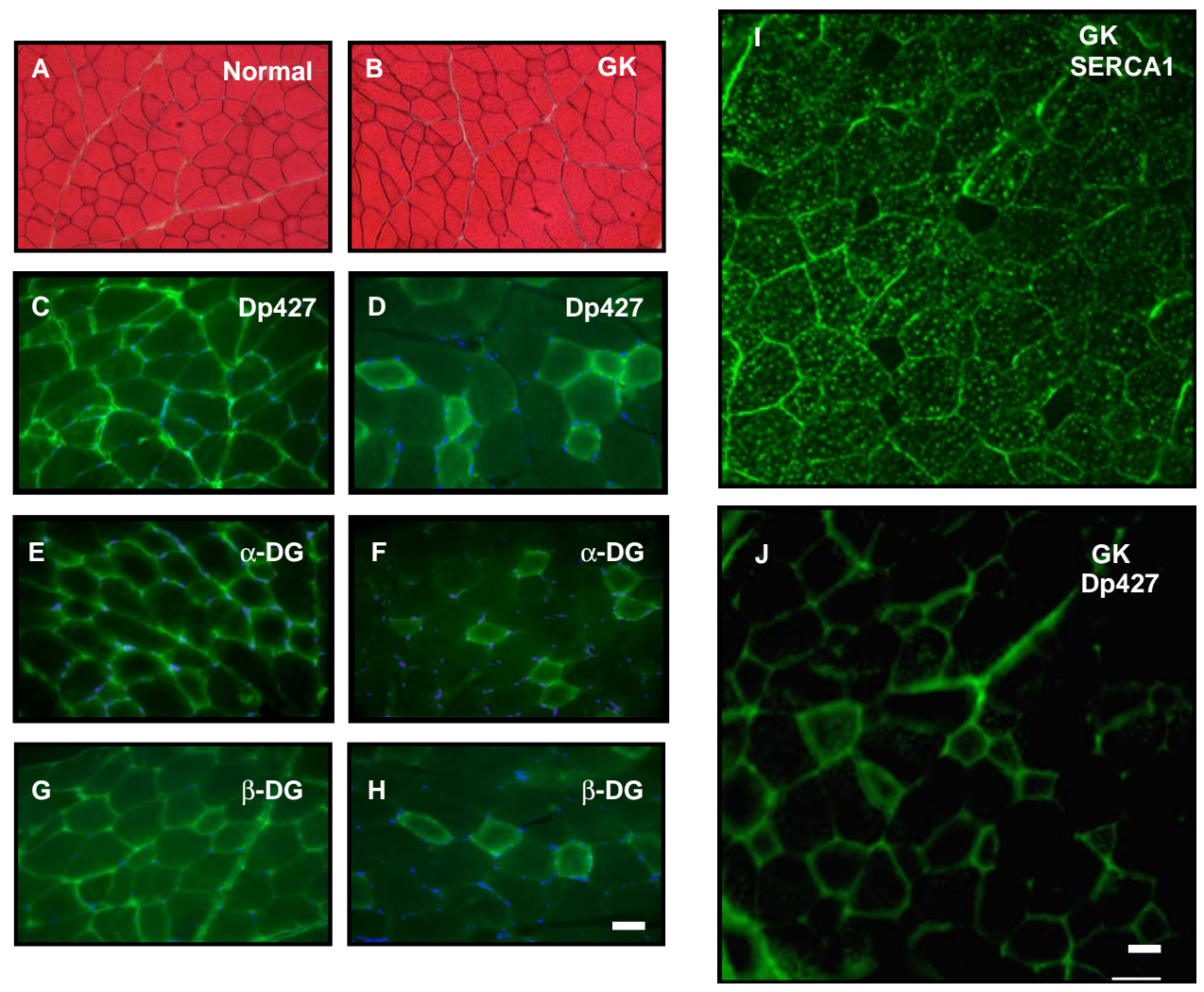

Fig. 7. Immunofluorescence localization of dystrophin and associated glycoproteins in GK skeletal muscle. Transversely cut cryosections stained with eosin (A, B) and labelled with antibodies to dystrophin (C, D, J; Dp427), $\alpha$-dystroglycan (E, F; $\alpha$-DG), $\beta$ dystroglycan $\left(\mathrm{G}, \mathrm{H} ; \beta\right.$-DG), and the fast-twitch isoform of the sarcoplasmic reticulum $\mathrm{Ca}^{2+}$-ATPase (I; SERCA1). Nuclei were stained with DAPI. Bar $=40 \mu \mathrm{m}$.

muscle fibres exhibited a relatively even distribution of the members of the dystrophin-dystroglycan complex in the cellular periphery of most fibres, GK muscle sections showed a clear lack of these sarcolemmal proteins in selected fibres. To investigate a potential correlation between fibre type distribution and absence of dystro- phin in GK tissue, Fig. 7I, J, illustrates the labelling of serial sections. Since the SERCA1 isoform of the sarcoplasmic reticulum $\mathrm{Ca}^{2+}$-ATPase exclusively labels fast-twitch fibres, it can be employed as a reliable cell biological marker of fast versus slow fibres (Fig. 7I). The direct comparison between the localization of SERCA1 
and the patchy fibre staining pattern for the full-length dystrophin isoform Dp427 showed no apparent relationship between fibre type and the abnormal protein expression pattern. Abnormal dystrophin levels were found in both fast and slow fibres (Fig. 7J).

\section{Preserved histochemical and immunofluorescence labelling of muscle markers indicates a lack of general fibre degeneration in the GK rat model of type 2 diabetes}

In order to determine potential fibre degeneration in GK muscle due to the reduction of the dystrophindystroglycan complex, transverse cryosections were labelled for the presence and distribution of marker proteins using standard histochemical and immunofluorescence techniques. The serial sections of normal versus diabetic fibres in Fig. 8A-F show a relatively normal distribution of the mitochondrial marker succinate dehydrogenase and almost exclusively peripheral nucleation in myofibres. Haematoxylin and DAPI labelling revealed very little central positioning of nuclei, which is frequently observed in dystrophic muscle fibres. Thus, in contrast to the completely dystrophin-deficient MDX model of Duchenne muscular dystrophy, GK muscle with a partial reduction in the Dp427 isoform, does not appear to exhibit a dystrophic phenotype. The comparable immunofluorescence labelling patterns of the surface marker $\mathrm{Na}^{+} / \mathrm{K}^{+}$-ATPase, the extracellular matrix component laminin and the sarcoplasmic reticulum protein calsequestrin (Fig. 8G-L) are in agreement with this assessment. These findings confirm the immunoblot analysis of this study and showed no marked difference in the localization pattern of these key muscle proteins. Hence, no major structural abnormalities seem to exist in diabetic GK fibres.

\section{Discussion}

Major efforts are underway to define the molecular mechanisms that regulate glucose metabolism in insulinsensitive cells. Skeletal muscle is a key tissue responsible for insulin-stimulated glucose disposal and thus the major site of peripheral insulin resistance in type 2 diabetes (Baron et al., 1991). Impaired glucose transport in skeletal muscle leads to impaired whole body glucose uptake (DeFronzo, 1992). A combination of genetic and environmental factors is likely to contribute to the pathogenesis of this metabolic disorder (Moller, 2001). Our initial investigation into the subcellular location of the glucose transporter GLUT4 in basal, non-insulin stimulated muscle agrees with previous studies (Garvey et al., 1998) and suggests an abnormal accumulation of GLUT4 vesicles in a dense membrane region, from
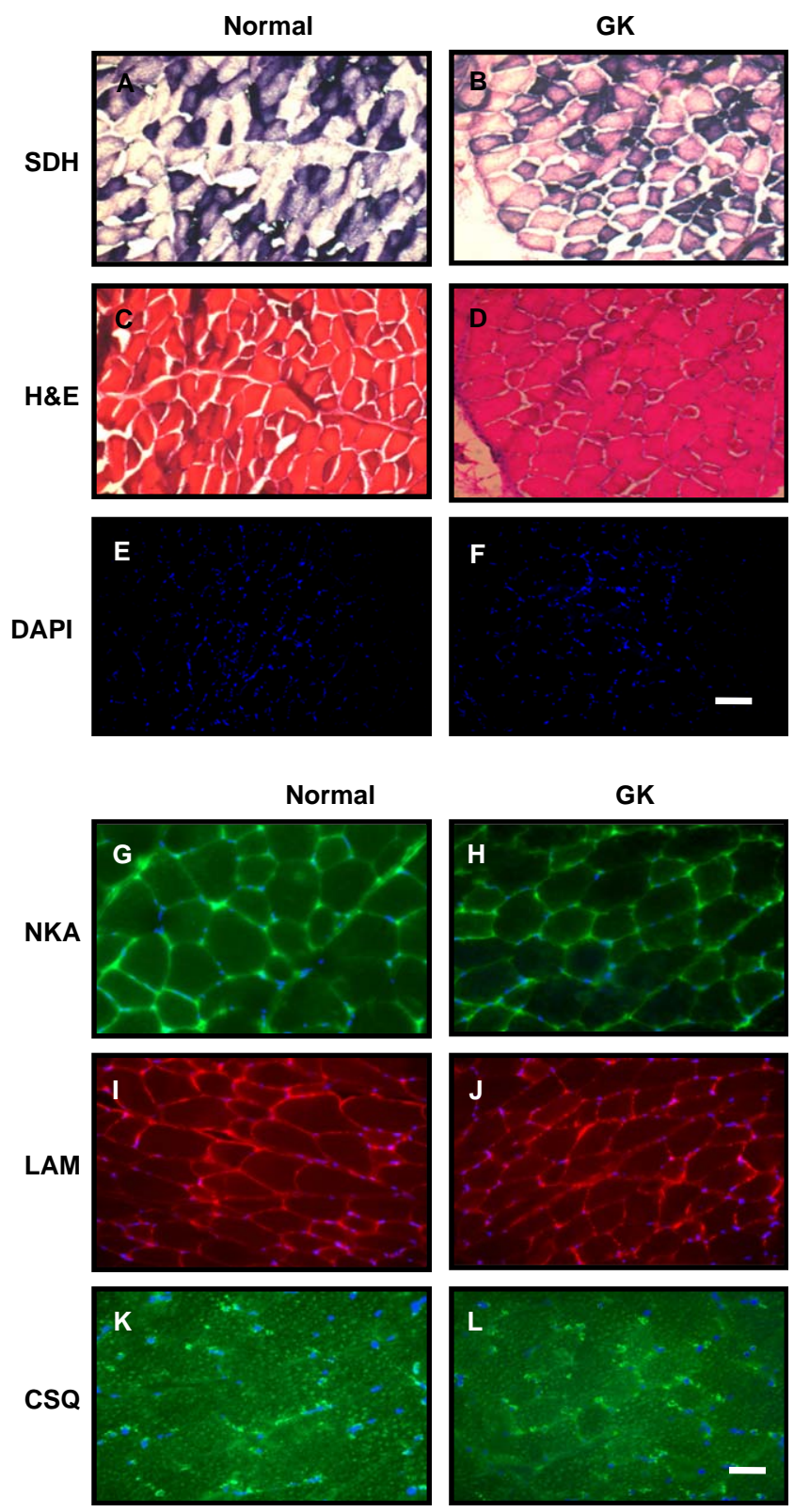

Fig. 8. Histochemical and immunofluorescence survey of GK skeletal muscle. In order to evaluate whether diabetic GK fibres show obvious signs of muscle pathology, transversely cut cryosections were stained with standard histological, histochemical and immunofluorescence techniques. Tissue sections labelled for succinate dehydrogenase activity (A, B; SDH), stained with haematoxylin and eosin (C, D; H\&E), DAPI (E, F; DAPI), and labelled with antibodies to markers of the surface membrane $\left(\mathrm{G}, \mathrm{H} ; \mathrm{Na}^{+} / \mathrm{K}^{+}\right.$-ATPase, NKA), the extracellular matrix (I, J; laminin, LAM), and the sarcoplasmic reticulum (K, L; calsequestrin, CSQ). Bars $=40 \mu \mathrm{m}(\mathrm{A}-\mathrm{F})$, $20 \mu \mathrm{m}$ (G-L). Cellular abnormalities that are commonly observed in dystrophic fibres such as necrosis, large variations in the size of myofibres, fibrosis, rounded contours of fibres, infiltration of immune cells and central nucleation, do not appear to be present in diabetic GK skeletal muscle. 
which insulin signalling may be unable to properly recruit the transporter molecule. Although expression levels of the insulin receptor, GLUT4 and associated signalling molecules are not affected in GK muscles, insulin resistance may result from the inability of a critical amount of GLUT4 units to reach the plasmalemma. Since the fusion of GLUT4 with the muscle surface membrane is essential for physiological glucose uptake, a regulatory defect in the rate-limiting process of GLUT4 trafficking and translocation is probably central to diabetic pathology. In this respect, the results presented in this report support the idea of a pathophysiological GLUT4 mechanism that may be involved in abnormal signalling in diabetic skeletal muscle.

The finding that the sarcolemmal marker $\beta$-dystroglycan is reduced in GK muscle preparations led to an in-depth investigation of the fate of the dystrophin-glycoprotein complex in diabetic skeletal muscle fibres. GK muscles clearly exhibit a drastic reduction in the membrane cytoskeletal component dystrophin and the two core dystroglycan proteins that form the linkage between the extracellular matrix protein laminin and cortical actin in normal muscle. The abnormal expression pattern does not appear to correlate with the fast versus the slow fibre type. Since the disintegration of the dystrophin complex is the primary abnormality leading to fibre weakness in many common muscle diseases (Cohn and Campbell, 2000), we postulate that the disturbances within the surface dystrophin-glycoprotein complex may contribute to insulin resistance and abnormalities characteristic of diabetic GK skeletal muscle. We initiated this analysis because type 2 diabetes is associated with skeletal muscle weakness (Andersen et al., 2004). Originally we expected a slight disturbance of the surface membrane in diabetic fibres linked to insulin resistance, but were surprised when we discovered a dramatic reduction in dystrophin and some of its associated glycoproteins, both by immunoblotting and immunofluorescence microscopy.

The selective reduction in dystroglycans is probably due to the fact that the $\alpha / \beta$-dystroglycan subcomplex, which forms the trans-sarcolemmal backbone of the dystrophin-glycoprotein complex, is directly linked to the Dp427 isoform, but sarcoglycans and laminin are indirectly associated with dystrophin. However, due to the lack of the complete pathophysiological scenario in diabetic muscle, from our initial analysis of the GK rat model, it is difficult to deduce the mechanism underlying the loss of the dystrophin-dystroglycan complex in selected diabetic myofibres. At this stage it is not possible to link these downstream events to one or more primary defects in type 2 diabetes (Almind et al., 2001). Since dystrophin forms an integral part of a multi-functional surface complex, various scenarios are possible. The dystrophin-containing supramolecular membrane assembly is involved in sarcolemmal stabili- zation during excitation-contraction-relaxation cycles, signal transduction and receptor anchoring to the cellular periphery (Culligan et al., 1998). Thus the abnormal expression or reduced affinity of any binding partner within this complex membrane arrangement may have an indirect effect on dystrophin, which in turn has an influence on the dystroglycans and associated elements. Interestingly, the expression of the dystrophinlinked signalling element syntrophin and its associated enzyme nNOS (Grozdanovic and Baumgarten, 1999) is severely affected in GK fibres.

Nitric oxide, a readily diffusible and short-lived agent, is formed intracellularly by the action of NOS enzymes and interacts with an array of molecular targets in- and outside the cell. In skeletal muscle, nitric oxide mediates diverse functions related to fibre development, metabolism, contraction and blood flow (Lee et al., 1994; Kobzik et al., 1994; Roberts et al., 1997). Loss of nNOS may also result in aberrant regulation of adrenergic vasoconstriction (Thomas et al., 1998). In addition, nitric oxide represents an anti-inflammatory and cytoprotective factor (Wehling et al., 2001) suggesting that a reduction in nNOS may trigger muscle pathology (Rando, 2001). This has been shown to be the case in sarcoglycan-deficient muscles from patients afflicted with limb-girdle muscular dystrophy (Crosbie et al., 2002). In agreement with a reduced nNOS expression in GK muscle is the recent report by Kashyap et al. (2005) describing impaired nitric oxide synthase activity in skeletal muscle from type 2 diabetic patients. Thus, if the dystrophin-dystroglycan complex is reduced in diabetic fibres, this may lead directly to a structural weakening of the muscle fibre periphery and indirectly to abnormal signal transduction due to the loss of important enzymes, such as nNOS.

In various forms of muscular dystrophy, the disintegration of the dystrophin-glycoprotein complex interrupts the trans-plasmalemmal linkage between the actin membrane cytoskeleton and the extracellular matrix element laminin (Ohlendieck, 1996; Culligan et al., 1998). The complete absence of the full-length Dp427 isoform of dystrophin renders muscle fibres more susceptible to necrosis (Campbell, 1995; Cohn and Campbell, 2000). The investigation of the fate of the dystrophin-dystroglycan complex in insulin-resistant tissue specimens, as reported here, suggests that a partial reduction in these surface proteins does not trigger general muscle degeneration. This assumption is based on the fact that GK muscle exhibits a persistent expression of calsequestrin-like proteins and adenylate kinase, muscle components that are greatly reduced in the MDX model of muscular dystrophy (Culligan et al., 2002; Ge et al., 2003). Creatine kinase and adenylate kinase provide a major nucleotide pathway, and the lack of adenylate kinase suggests an abnormal regulation of nucleotide ratios in MDX fibres (Ge et al., 2003). GK 
muscle does not seem to show this metabolic deficiency. Mass spectrometry-based proteomics revealed no statistically significant difference in the expression of major contractile proteins and enzymes in normal versus diabetic fibres demonstrating the lack of major protein degradation. This is in agreement with the finding that no low-molecular-mass fragments of the SERCA1 enzyme were found in GK preparations. The partial loss of dystrophin does not appear to trigger extensive proteolysis. Histochemical and immunofluorescence analyses confirmed the lack of a dystrophic GK phenotype, since most diabetic fibres do not show the typical signs of muscular dystrophy such as central nucleation, a large variation in fibre size, necrosis, fibrosis, infiltration of immune cells or rounded contours of myofibres (Ohlendieck and Campbell, 1991).

The preserved expression levels and subcellular locations of muscle markers of the sarcolemma, sarcoplasmic reticulum, extracellular matrix and mitochondria in diabetic fibres, which agree with previous cell biological studies of GK muscle (Yasuda et al., 2002), also demonstrate a lack of major muscle pathology due to abnormal dystrophin expression in these types of muscle. In severe forms of muscular dystrophy, the primary or secondary complete deficiency in dystrophin leads to a common pathological pathway that eventually triggers muscle degeneration (Culligan et al., 1998). In diabetes, the partial reduction in dystrophin appears to trigger a considerably milder phenotype. However, on the molecular level the reduced expression of dystrophin and some of its associated elements might cause impaired signalling and thus may play a pathophysiological role in some metabolic pathways. Many researchers in the field of muscular dystrophy have accepted that abnormal $\mathrm{Ca}^{2+}$ fluxes play a major part in muscle cell destruction (Alderton and Steinhardt, 2000; Ohlendieck, 2005). Since dystrophin is reduced in diabetic muscle, the ion-regulatory apparatus might also be affected in type 2 diabetes. We could previously show that in a drug-induced animal model of type 1 diabetes the $\mathrm{Ca}^{2+}$-binding element calsequestrin is drastically up-regulated, probably compensating for abnormal accumulations of elevated intracellular $\mathrm{Ca}^{2+}$ levels in diabetic muscle fibres (Howarth et al., 2002). However, screening of diabetic GK muscle samples with a library of monoclonal antibodies to key ion-handling proteins did not detect abnormal expression levels in signalling elements that might be indirectly linked to insulin resistance. Thus, the loss of nNOS might represent the most important pathophysiological consequence of the reduced dystrophin levels in GK fibres.

In conclusion, the analysis of the dystrophin-dystroglycan complex in GK skeletal muscle demonstrated a loss of key membrane cytoskeletal elements in diabetic fibres. This suggests a weakened muscle surface mem- brane in selected fibres and may cause in the long term an enhanced rate of micro-rupturing during excitationcontraction-relaxation cycles. The reduced expression of syntrophin and nNOS may aggravate the diabetic condition due to abnormal signalling and decreased cytoprotective mechanisms. The disturbance of the dystrophin complex may affect the integrity of the cortical actin cytoskeleton and its linkage to the sarcolemma. This may interfere with the ability of GLUT4 proteins to correctly fuse with the surface membrane and thereby inhibit glucose uptake. Consequently, abnormal expression of dystrophin, dystroglycans and syntrophin may exacerbate the insulin resistance characteristic of non-obese, type 2 diabetic skeletal muscle fibres. In seeking to develop new therapeutic strategies, the rescue of dystrophin-associated proteins may play a key role in preventing the abnormal diabetic phenotype.

\section{Acknowledgments}

Research was supported by project Grants from the Irish Health Research Board (HRB-RP/2005/3) and the European Commission (HPRN-CT-2002-00331), as well as equipment Grants from the Irish Health Research Board (HRB-EQ/2003/3, HRB-EQ/2004/2).

\section{References}

Abdel-Halim, S.M., Guenifi, A., Luthman, H., Grill, V., Efendic, S., Ostenson, C.G., 1994. Impact of diabetic inheritance on glucose tolerance and insulin secretion in spontaneously diabetic GK-Wistar rats. Diabetes 43, 281-288.

Alderton, J.M., Steinhardt, R.A., 2000. Calcium influx through calcium leak channels is responsible for the elevated levels of calcium-dependent proteolysis in dystrophic myotubes. J. Biol. Chem. 275, 9452-9460.

Almind, K., Doria, A., Kahn, C.R., 2001. Putting the genes for type II diabetes on the map. Nat. Med. 7, 277-279.

Andersen, H., Nielsen, S., Mogensen, C.E., Jakobsen, J., 2004. Muscle strength in type 2 diabetes. Diabetes 53, 1543-1548.

Baron, A.D., Laakso, M., Brechtel, G., Edelman, S.V., 1991. Mechanism of insulin resistance in insulin-dependent diabetes mellitus: a major role for reduced skeletal muscle blood flow. J. Clin. Endocrinol. Metab. 73, 637-643.

Boord, J.B., Graber, A.L., Christman, J.W., Powers, A.C., 2001. Practical management of diabetes in critically ill patients. Am. J. Respir. Crit. Care Med. 164, 1763-1767.

Bradd, S.J., Dunn, M.J., 1993. Analysis of membrane proteins by western blotting and enhanced chemiluminescence. Methods Mol. Biol. 19, 211-218.

Bradford, M.M., 1976. A rapid and sensitive method for the quantitation of microgram quantities of protein utilizing the principle of protein-dye binding. Anal. Biochem. 72, 248-254. 
Campbell, K.P., 1995. Three muscular dystrophies: loss of cytoskeleton-extracellular matrix linkage. Cell 80, 675-679.

Cohn, R.D., Campbell, K.P., 2000. Molecular basis of muscular dystrophies. Muscle Nerve 23, 1456-1471.

Crosbie, R.H., Barresi, R., Campbell, K.P., 2002. Loss of sarcolemma nNOS in sarcoglycan-deficient muscle. FASEB J. 16, 1786-1791.

Culligan, K., Mackey, A., Finn, D., Maguire, P.B., Ohlendieck, K., 1998. Role of dystrophin isoforms and associated glycoproteins in muscular dystrophy (review). Int. J. Mol. Med. 2, 639-648.

Culligan, K., Banville, N., Dowling, P., Ohlendieck, K., 2002. Drastic reduction of calsequestrin-like proteins and impaired calcium binding in dystrophic mdx muscle. J. Appl. Physiol. 92, 435-445.

Cushman, S.W., Goodyear, L.J., Pilch, P.F., Ralston, E., Galbo, H., Ploug, T., Kristiansen, S., Klip, A., 1998. Molecular mechanisms involved in GLUT4 translocation in muscle during insulin and contraction stimulation. Adv. Exp. Med. Biol. 441, 63-71.

Dadke, S.S., Li, H.C., Kusari, A.B., Begum, N., Kusari, J., 2000. Elevated expression and activity of protein-tyrosine phosphatase 1B in skeletal muscle of insulin-resistant type II diabetic Goto-Kakizaki rats. Biochem. Biophys. Res. Commun. 274, 583-589.

DeFronzo, R.A., 1992. Pathogenesis of type 2 (non-insulin dependent) diabetes mellitus: a balanced overview. Diabetologia 35, 389-397.

Doran, P., Dowling, P., Lohan, J., McDonnell, K., Poetsch, S., Ohlendieck, K., 2004. Subproteomics analysis of $\mathrm{Ca}^{2+}$ binding proteins demonstrates decreased calsequestrin expression in dystrophic mouse skeletal muscle. Eur. J. Biochem. 271, 3943-3952.

Dowling, P., Doran, P., Ohlendieck, K., 2004. Drastic reduction of sarcalumenin in Dp427 (dystrophin of $427 \mathrm{kDa}$ )-deficient fibres indicates that abnormal calcium handling plays a key role in muscular dystrophy. Biochem. J. 379, 479-488.

Dunn, M.J., Bradd, S.J., 1993. Separation and analysis of membrane proteins by SDS-polyacrylamide gel electrophoresis. Methods Mol. Biol. 19, 203-210.

Etgen Jr., G.J., Fryburg, D.A., Gibbs, E.M., 1997. Nitric oxide stimulates skeletal muscle glucose transport through a calcium/contraction- and phosphatidylinositol-3-kinaseindependent pathway. Diabetes 46, 1915-1919.

Froemming, G.R., Ohlendieck, K., 2001. The native dihydropyridine receptor exists as a supramolecular complex in skeletal muscle. Cell. Mol. Life Sci. 58, 312-320.

Garvey, W.T., Maianu, L., Zhu, J.H., Brechtel-Hook, G., Wallace, P., Baron, A.D., 1998. Evidence for defects in the trafficking and translocation of GLUT4 glucose transporters in skeletal muscle as a cause of human insulin resistance. J. Clin. Invest. 101, 2377-2386.

Ge, Y., Molloy, M.P., Chamberlain, J.S., Andrews, P.C., 2003. Proteomic analysis of $\mathrm{mdx}$ skeletal muscle: great reduction of adenylate kinase 1 expression and enzymatic activity. Proteomics 3, 1895-1903.

Glover, L., Quinn, S., Ryan, M., Pette, D., Ohlendieck, K., 2002. Supramolecular calsequestrin complex: protein-protein interactions in chronic low-frequency stimulated muscle, postnatal development and ageing. Eur. J. Biochem. 269, 4607-4616.

Grozdanovic, Z., Baumgarten, H.G., 1999. Nitric oxide synthase in skeletal muscle fibers: a signaling component of the dystrophin-glycoprotein complex. Histol. Histopathol. 14, 243-256.

Howarth, F.C., Glover, L., Culligan, K., Qureshi, M.A., Ohlendieck, K., 2002. Calsequestrin expression and calcium binding is increased in streptozotocin-induced diabetic rat skeletal muscle though not in cardiac muscle. Pflügers Arch. 444, 52-58.

Kahn, B.B., Rossetti, L., Lodish, H.F., Charron, M.J., 1991. Decreased in vivo glucose uptake but normal expression of GLUT1 and GLUT4 in skeletal muscle of diabetic rats. J. Clin. Invest. 87, 2197-2206.

Kameya, S., Miyagoe, Y., Nonaka, I., Ikemoto, T., Endo, M., Hanaoka, K., Nabeshima, Y., Takeda, S., 1999. Alpha1syntrophin gene disruption results in the absence of neuronal-type nitric-oxide synthase at the sarcolemma but does not induce muscle degeneration. J. Biol. Chem. 274, 2193-2200.

Kashyap, S.R., Roman, L.J., Lamont, J., Masters, B.S., Bajaj, M., Suraamornkul, S., Belfort, R., Berria, R., Kellogg Jr., D.L., Liu, Y., DeFronzo, R.A., 2005. Insulin resistance is associated with impaired nitric oxide synthase activity in skeletal muscle of type 2 diabetic subjects. J Clin. Endocrinol. Metab. 90, 1100-1105.

King, H., Aubert, R.E., Herman, W.H., 1998. Global burden of diabetes, 1995-2025: prevalence, numerical estimates, and projections. Diabetes Care 21, 1414-1431.

Kitahara, A., Toyota, T., Kakizaki, M., Goto, Y., 1978. Activities of hepatic enzymes in spontaneous diabetes rats produced by selective breeding of normal Wistar rats. Tohoku J. Exp. Med. 126, 7-11.

Klip, A., Ramlal, T., Young, D.A., Holloszy, J.O., 1987. Insulin-induced translocation of glucose transporters in rat hindlimb muscles. FEBS Lett. 224, 224-230.

Kobzik, L., Reid, M.B., Bredt, D.S., Stamler, J.S., 1994. Nitric oxide in skeletal muscle. Nature 372, 546-548.

Krook, A., Kawano, Y., Song, X.M., Efendic, S., Roth, R.A., Wallberg-Henriksson, H., Zierath, J.R., 1997. Improved glucose tolerance restores insulin-stimulated Akt kinase activity and glucose transport in skeletal muscle from diabetic Goto-Kakizaki rats. Diabetes 46, 2110-2114.

Lee, K.H., Baek, M.Y., Moon, K.Y., Song, W.K., Chung, C.H., Ha, D.B., Kang, M.S., 1994. Nitric oxide as a messenger molecule for myoblast fusion. J. Biol. Chem. 269, 14371-14374.

Moller, D.E., 2001. New drug targets for type 2 diabetes and the metabolic syndrome. Nature 414, 821-827.

Mulvey, C., Ohlendieck, K., 2003. Use of continuous-elution gel electrophoresis as a preparative tool for blot overlay analysis. Anal. Biochem. 319, 122-130.

Murray, B.E., Ohlendieck, K., 1997. Cross-linking analysis of the ryanodine receptor and $\alpha_{1}$-dihydropyridine receptor in rabbit skeletal muscle. Biochem. J. 324, 689-696.

Oak, S.A., Russo, K., Petrucci, T.C., Jarrett, H.W., 2001. Mouse alpha1-syntrophin binding to Grb2: further evidence of a role for syntrophin in cell signaling. Biochemistry $40,11270-11278$. 
Ohlendieck, K., 1996. Towards an understanding of the dystrophin-glycoprotein complex: linkage between the extracellular matrix and the subsarcolemmal membrane cytoskeleton. Eur. J. Cell Biol. 69, 1-10.

Ohlendieck, K., 2005. The pathophysiological role of impaired calcium handling in muscular dystrophy. In: Winder, S.J. (Ed.), Molecular Mechanisms of Muscular Dystrophies. Landes Bioscience, Georgetown, TX, pp. 170-180 (Chapter 15).

Ohlendieck, K., Campbell, K.P., 1991. Dystrophin-associated proteins are greatly reduced in skeletal muscle from $\mathrm{mdx}$ mice. J. Cell Biol. 115, 1685-1694.

Okamoto, H., Accili, D., 2003. In vivo mutagenesis of the insulin receptor. J. Biol. Chem. 278, 28359-28362.

Petersen, K.F., Shulman, G.I., 2002. Pathogenesis of skeletal muscle insulin resistance in type 2 diabetes mellitus. Am. J. Cardiol. 90, 11G-18G.

Portha, B., Serradas, P., Bailbe, D., Suzuki, K., Goto, Y., Giroix, M.H., 1991. Beta-cell insensitivity to glucose in the GK rat, a spontaneous nonobese model for type II diabetes. Diabetes 40, 486-491.

Rando, T.A., 2001. Role of nitric oxide in the pathogenesis of muscular dystrophies: a 'two hit' hypothesis of the cause of muscle necrosis. Microsc. Res. Tech. 55, 223-235.

Roberts, C.K., Barnard, R.J., Scheck, S.H., Balon, T.W., 1997. Exercise-stimulated glucose transport in skeletal muscle is nitric oxide dependent. Am. J. Physiol. 273, E220-E225.

Scheen, A.J., 2003. Pathophysiology of type 2 diabetes. Acta Clin. Belg. 58, 335-341.

Schmitz-Peiffer, C., Whitehead, J.P., 2003. IRS-1 regulation in health and disease. IUBMB Life 55, 367-374.

Song, X.M., Kawano, Y., Krook, A., Ryder, J.W., Efendic, S., Roth, R.A., Wallberg-Henriksson, H., Zierath, J.R., 1999. Muscle fiber type-specific defects in insulin signal transduc- tion to glucose transport in diabetic GK rats. Diabetes 48 , 664-670.

Sowers, J.R., Frohlich, E.D., 2004. Insulin and insulin resistance: impact on blood pressure and cardiovascular disease. Med. Clin. North Am. 88, 63-82.

Steiler, T.L., Galuska, D., Leng, Y., Chibalin, A.V., Gilbert, M., Zierath, J.R., 2003. Effect of hyperglycemia on signal transduction in skeletal muscle from diabetic Goto-Kakizaki rats. Endocrinology 144, 5259-5267.

Thomas, G.D., Sander, M., Lau, K.S., Huang, P.L., Stull, J.T., Victor, R.G., 1998. Impaired metabolic modulation of alpha-adrenergic vasoconstriction in dystrophin-deficient skeletal muscle. Proc. Natl. Acad. Sci. USA 95, 15090-15095.

Towbin, H., Staehelin, T., Gordon, J., 1979. Electrophoretic transfer of proteins from polyacrylamide gels to nitrocellulose sheets: procedure and some applications. Proc. Natl. Acad. Sci. USA 76, 4350-4354.

Wehling, M., Spencer, M.J., Tidball, J.G., 2001. A nitric oxide synthase transgene ameliorates muscular dystrophy in $\mathrm{mdx}$ mice. J. Cell Biol. 155, 123-131.

Witte, K., Jacke, K., Stahrenberg, R., Arlt, G., Reitenbach, I., Schilling, L., Lemmer, B., 2002. Dysfunction of soluble guanylyl cyclase in aorta and kidney of Goto-Kakizaki rats: influence of age and diabetic state. Nitric Oxide 6, $85-95$.

Yang, B., Jung, D., Motto, D., Meyer, J., Koretzky, G., Campbell, K.P., 1995. SH3 domain-mediated interaction of dystroglycan and Grb2. J. Biol. Chem. 270, 11711-11714.

Yasuda, K., Nishikawa, W., Iwanaka, N., Nakamura, E., Seino, Y., Tsuda, K., Ishihara, A., 2002. Abnormality in fibre type distribution of soleus and plantaris muscles in non-obese diabetic Goto-Kakizaki rats. Clin. Exp. Pharmacol. Physiol. 29, 1001-1008.

Zimmet, P., Alberti, K.G., Shaw, J., 2001. Global and societal implications of the diabetes epidemic. Nature 414, 782-787. 